\title{
The effect of the waiting room's environment on level of anxiety experienced by children prior to dental treatment: a case control study
}

Avia Fux-Noy* (1), Maayan Zohar, Karin Herzog, Aviv Shmueli, Elinor Halperson, Moti Moskovitz and Diana Ram

\begin{abstract}
Background: In addition to visit purpose, one of the environmental factors that can cause anxiety prior to dental treatment includes the waiting room experience, specifically the amount of time spent awaiting treatment and the waiting room environment. The purpose of this study was to compare the effect of the waiting room's environment on the level of anxiety experienced by children in multisensory and traditional waiting rooms.

Methods: Case control study. Test group waited for treatment in a multisensory waiting room, which consisted of a lighting column that children could touch and climb; as well as, rhythmic music played on loudspeakers. Control group waited for treatment in a traditional waiting room. Study participants were asked to answer the "Venham Picture Test", a dental anxiety scale, while in the waiting room prior to entering the treatment room. Chi-squared, Fisher's Exact tests, and linear regression were utilized. A p-value less than 0.05 was considered statistically significant.
\end{abstract}

Results: No significant difference in dental anxiety scores was found between the test and control groups according to waiting room type $(p>$.05). Dental anxiety was significantly higher in patients who had longer waiting time prior to treatment $(p=0.019)$. In addition, dental anxiety was significantly associated with visit purpose $(p<.001)$ : children waiting for dental examination or those scheduled for dental treatment with conscious sedation were less anxious than children waiting for emergency treatment.

Conclusions: A sensory adapted waiting room environment may be less important in reducing children's anxiety prior to dental treatment. Children's dental anxiety can be reduced by preventing emergency treatments, scheduling routine dental visits and decreasing waiting time.

Trial registration: TRN NCT03197129, date of registration June 20, 2017.

Keywords: Waiting room, Dental anxiety, Multisensory environment

\section{Background}

It has been estimated that about $11 \%$ of children and adolescents suffer from dental anxiety [1]. The level of the subject's dental anxiety is affected by environmental factors and personality traits [2]. One of the environmental factors that can cause anxiety prior to dental treatment includes the waiting room experience [3], specifically the amount of time spent awaiting treatment and the waiting

\footnotetext{
* Correspondence: fuxavia@gmail.com

Department of Pediatric Dentistry, Hadassah School of Dental Medicine, P.O.Box 12272, 9112102 Jerusalem, Israel
}

room environment [4]. Existing literature addressing the waiting room environment and atmosphere evaluated different methods to reduce anxiety in the waiting room, such as exposure to positive images of dentistry $[5,6]$, aromatherapy [7, 8], and music [9-11].

The Snoezelen environment, which consists of a multisensory adapted environment coupled with clientcentered therapy, provides a soothing atmosphere for patients with cognitive impairment [12]. The sensory adapted dental environment, developed based on the Snoezelen environment, has been found to significantly

(c) The Author(s). 2019 Open Access This article is distributed under the terms of the Creative Commons Attribution 4.0 International License (http//creativecommons.org/licenses/by/4.0/), which permits unrestricted use, distribution, and reproduction in any medium, provided you give appropriate credit to the original author(s) and the source, provide a link to the Creative Commons license, and indicate if changes were made. The Creative Commons Public Domain Dedication waiver (http://creativecommons.org/publicdomain/zero/1.0/) applies to the data made available in this article, unless otherwise stated. 
reduce dental anxiety and maladaptive behaviors, while facilitating a calming effect in the dental clinic among children during routine dental prophylactic cleaning [13-15]. While this technique has been studied in the operating room during operative treatment, the impact of waiting in a multisensory adapted environment on anxiety prior to dental treatment has not been evaluated. Hence, the aim of this study was to compare the effect of multisensory and traditional waiting room environments on the level of dental anxiety experienced by children prior to dental treatment.

\section{Methods}

\section{Study population}

Participants were recruited from the pediatric dental clinic at Hadassah Ein Kerem. Inclusion criteria: males and females between 3 and 10 years of age, who were waiting for a dental examination or dental treatment. Exclusion criteria: patients who have developmental disorders and were mentally or cognitively unable to understand or answer the Venham Picture Test (VPT) [16] that assesses anxiety before treatment; as well as, patients accepted immediately on arrival for their dental visit without spending time in the waiting room. Written informed consent was obtained from all parents/guardians of the participants included in the study.

\section{Study design}

This is a case control study. The test group was waiting for dental treatment in the multisensory waiting room: a small room $(2.5 \mathrm{mx} 2.5 \mathrm{~m})$ located inside the pediatric dental clinic, with 6 seats. The multisensory environment consisted of a lighting column that children could touch and climb on. Auditory stimuli included rhythmic music, played on loudspeakers. The control group waited for dental treatment in the traditional waiting room, located in the dental school lobby outside the pediatric dental clinic. This waiting room consisted of ten seats in one row facing the reception desk, and was air-conditioned, well-lit, without posters or paintings on the walls, and no reading material. Since the test group's waiting room was closer to the operating rooms, it is possible that noise from the operating rooms was heard in the test group's waiting room. However, music was played in the test waiting room, which may have concealed these sounds. Participants were randomly assigned to the test or control group by a toss of a coin.

Participants were asked to answer the VPT, a dental anxiety scale, while waiting in the waiting room just before entering the treatment room. VPT is widely used and easily administered. In this test, children were presented with eight cards, with two figures on each card: one anxious figure and one non-anxious figure. The main investigator, wearing a white dental uniform, asked the children to choose the figure from each pair that described how they felt at that particular time. All cards were shown in their numbered order. If an anxious figure was chosen, a score of one was recorded. If a nonanxious figure was chosen, a score of zero was recorded. A measure of anxiety was obtained by totaling the number of times the child picked the figure depicting the anxious state (minimum score 0 ; maximum score 8).

Additional data including gender, age, waiting time, purpose of visit, parent/guardian accompanying child, child's dental history and experience was collected from the parents by the main investigator.

\section{Sample size and power calculation}

A pilot study was conducted with 40 subjects per study group. Based on this study, a power analysis was completed to determine an appropriate sample size. To achieve a significance level at the 95th percentile confidence level and a power of $80 \%$, with a 0.5 estimated effect size, the sample size was calculated to be 51 subjects in each group.

\section{Ethical considerations}

Study protocol was approved by the Institutional Human Subjects Ethics Committee of Hadassah Medical Organization IRB, Jerusalem, Israel. All procedures performed were in accordance with the ethical standards of the institutional and national research committee. The study protocol was also enrolled, and the full trial protocol can be accessed at clinicaltrials.gov (NCT03197129). Detailed information in simple non-technical language was provided in advance and parents/guardians of all patients included in the study were requested to sign an informed consent. No compensation was provided for participating patients.

\section{Statistical analysis}

Data analysis was performed using statistical software (Stata version 12.1, StataCorp). Descriptive statistics were tabulated for the demographic and clinical characteristics. Chi-squared and Fisher's Exact tests were utilized to test the association between the categorical variables and waiting room type. A $\mathrm{T}$ test with unequal variance was used to test the association between VPT score and waiting room type. We estimated unadjusted and adjusted slopes from linear regression to examine the association between VPT score and waiting time; as well as, waiting room type. For this analysis, a $p$-value less than 0.05 was considered statistically significant.

\section{Results}

One hundred twenty-two children were recruited for this study. Nine dropped out since they did not answer the VPT (due to shyness or unwillingness). One hundred and 
thirteen children participated in the study: 61 males (54\%) and 52 females (46\%). Age range was 3-10 years, with an average age of 5.7 years $(\mathrm{SD}=2)$. The test group comprised of 56 children and the control group comprised of 57 children. Demographic and clinical characteristics of the groups are presented in Table 1 . There was a significant difference between the test and control group in regards to visit purpose (Fisher's Exact, $p<.001$ ): more children in the test group waited for dental treatment with oral conscious sedation, while more children in the control group waited for a dental examination or emergency treatment. There was no significant difference in gender, age, waiting time, dental history, dental experience or patient's escort between the two groups (Table 1).

There was no significant difference in mean VPT scores between the two groups with regards to room type ( $\mathrm{t}(95)=0.668, p>.05$ ) (Table 2). In order to overcome the difference in visit purpose, further analysis evaluating the subset of patients only treated with conscious sedation found no significant difference in mean VPT scores between groups ( $t$ (53) $=.346$, $p>.05$ ) (Table 2). There was a significant association between VPT scores and visit purpose $(\mathrm{F}(3,109)=$
5.03, $p<.001)$. Mean VPT scores and visit purpose are presented in Table 3. Those who presented for an emergency/pain visit had significantly higher VPT score $(P<0.001)$. The unadjusted linear regression analysis found a significant association between VPT score and waiting time, with a longer waiting time associated with higher VPT score $(p=0.019)$. This association was still significant even after adjusting by room type, age and gender $(p=0.013)$. There was no association between VPT score and type of waiting room (Table 4). Mean VPT scores and waiting time are presented in Table 5 .

\section{Discussion}

Nonverbal communication is a behavior management technique used by pediatric dentists $[17,18]$. A childfriendly atmosphere in the clinic is one aspect of this technique. Jayakaran et al. [19] evaluated the pediatric dental operatory environment and found that cartoonpainted walls, toys, and a scented environment reduced anxiety in children. In this current study we focused on the pediatric dental waiting room environment. We found no significant difference in the anxiety of children

Table 1 Demographic and clinical characteristics by waiting room type

\begin{tabular}{|c|c|c|c|c|c|c|c|c|}
\hline & & \multicolumn{2}{|c|}{$\begin{array}{l}\text { Total } \\
(N=113)\end{array}$} & \multicolumn{2}{|c|}{$\begin{array}{l}\text { Test Group } \\
\text { Multisensory } \\
\text { Waiting Room } \\
(N=56)\end{array}$} & \multicolumn{2}{|c|}{$\begin{array}{l}\text { Control Group } \\
\text { Conventional } \\
\text { Waiting Room } \\
(N=57)\end{array}$} & \multirow[t]{2}{*}{ Test statistic, $P$-value } \\
\hline & & $\begin{array}{l}\text { Freq.I } \\
\text { Mean }\end{array}$ & SD\\
% & $\begin{array}{l}\text { Freq.l } \\
\text { Mean }\end{array}$ & $\mathrm{SD \backslash \%}$ & $\begin{array}{l}\text { Freq.l } \\
\text { Mean }\end{array}$ & $\mathrm{SD \backslash \%}$ & \\
\hline \multirow[t]{2}{*}{ Gender } & Male & 61 & $54 \%$ & 33 & $59 \%$ & 28 & $49 \%$ & \multirow[t]{2}{*}{$X^{2}(1)=.798, p>.05$} \\
\hline & Female & 52 & $46 \%$ & 23 & $41 \%$ & 29 & $51 \%$ & \\
\hline \multicolumn{2}{|l|}{ Age (years) } & 5.68 & 1.98 & 5.63 & 1.87 & 5.73 & 2.1 & $\mathrm{t}(95)=0.28, p>.05$ \\
\hline \multicolumn{2}{|c|}{ Waiting length (minutes) } & 20.51 & 22.11 & 22.43 & 26.5 & 18.63 & 16.75 & $\mathrm{t}(95)=-.909, p>.05$ \\
\hline \multirow[t]{7}{*}{ Visit purpose } & Examination & 21 & $19 \%$ & 0 & $0 \%$ & 21 & $37 \%$ & \multirow[t]{7}{*}{ Fisher's Exact, $p<.001$} \\
\hline & Emergency & 13 & $11 \%$ & 1 & $2 \%$ & 12 & $21 \%$ & \\
\hline & Treatment- no sedation & 4 & $3.5 \%$ & 2 & $4 \%$ & 2 & $3.5 \%$ & \\
\hline & Treatment with preoperative sedation- midazolam & 32 & $28 \%$ & 23 & $41 \%$ & 9 & $16 \%$ & \\
\hline & Treatment with preoperative sedation- atarax & 36 & $32 \%$ & 25 & $45 \%$ & 11 & $19 \%$ & \\
\hline & Treatment with sedation- $\mathrm{N}_{2} \mathrm{O}$ & 4 & $3.5 \%$ & 2 & $4 \%$ & 2 & $3.5 \%$ & \\
\hline & Treatment with preoperative sedation- valium & 3 & $3 \%$ & 3 & $5 \%$ & 0 & $0 \%$ & \\
\hline \multirow[t]{3}{*}{ Dental history } & None & 4 & $4 \%$ & 1 & $2 \%$ & 3 & $5 \%$ & \multirow[t]{3}{*}{ Fisher's Exact, $p>.05$} \\
\hline & Examination only & 26 & $23 \%$ & 12 & $21 \%$ & 14 & $25 \%$ & \\
\hline & Treatment & 83 & $73 \%$ & 43 & $77 \%$ & 40 & $70 \%$ & \\
\hline \multirow[t]{3}{*}{ Dental experience } & Positive & 60 & $53 \%$ & 34 & $61 \%$ & 26 & $46 \%$ & \multirow[t]{3}{*}{ Fisher's Exact, $p>.05$} \\
\hline & Negative & 49 & $43 \%$ & 21 & $37 \%$ & 28 & $49 \%$ & \\
\hline & NA & 4 & $4 \%$ & 1 & $2 \%$ & 3 & $5 \%$ & \\
\hline \multirow[t]{3}{*}{ Escort } & Mother & 58 & $51 \%$ & 31 & $55 \%$ & 27 & $47 \%$ & \multirow[t]{3}{*}{$x^{2}(1)=1.293, p>.05$} \\
\hline & Father & 39 & $35 \%$ & 19 & $34 \%$ & 20 & $35 \%$ & \\
\hline & Both & 16 & $14 \%$ & 6 & $11 \%$ & 10 & $18 \%$ & \\
\hline
\end{tabular}


Table 2 VPT scores according to waiting room type

\begin{tabular}{|c|c|c|c|c|}
\hline \multirow[t]{2}{*}{ VPT score } & \multicolumn{4}{|l|}{ Groups } \\
\hline & $\begin{array}{l}\text { Test } \\
N=56\end{array}$ & $\begin{array}{l}\text { Control } \\
N=57\end{array}$ & $\begin{array}{l}\text { Test- sedation only } \\
N=53\end{array}$ & $\begin{array}{l}\text { Control- sedation only } \\
N=22\end{array}$ \\
\hline & Freq (\%) & Freq (\%) & Freq (\%) & Freq (\%) \\
\hline 0 & $26(46.43 \%)$ & $22(38.60 \%)$ & $24(45.28 \%)$ & $11(50 \%)$ \\
\hline 1 & $6(10.71 \%)$ & $8(14.04 \%)$ & $6(11.32 \%)$ & $3(13.64 \%)$ \\
\hline 2 & $11(19.64 \%)$ & 9 (15.79\%) & $11(20.75 \%)$ & $3(13.64 \%)$ \\
\hline 3 & $4(7.14 \%)$ & $3(5.26 \%)$ & $4(7.55 \%)$ & 0 \\
\hline 4 & 0 & 7 (12.28\%) & 0 & 0 \\
\hline 5 & $4(7.14 \%)$ & $2(3.51 \%)$ & $4(7.55 \%)$ & $2(9.09 \%)$ \\
\hline 6 & $1(1.79 \%)$ & $3(5.26 \%)$ & $1(1.89 \%)$ & 0 \\
\hline 7 & $2(3.57 \%)$ & $1(1.75 \%)$ & $1(1.89 \%)$ & $1(4.55 \%)$ \\
\hline 8 & $2(3.57 \%)$ & $2(3.51 \%)$ & $2(3.77 \%)$ & $2(9.09 \%)$ \\
\hline Mean (SD) & $1.71(2.27)$ & $2(2.28)$ & $1.68(2.19)$ & $1.91(2.78)$ \\
\hline T-Test & \multicolumn{2}{|c|}{$\mathrm{t}(95)=.668, p>.05$} & \multicolumn{2}{|l|}{$\mathrm{t}(53)=.346, p>.05$} \\
\hline
\end{tabular}

waiting for dental treatment in a multisensory waiting room or conventional waiting room.

Coffey and Di Giusto [4] also found no difference between anxiety scores of patients in two different dental hospitals with different waiting room environments. In the Coffey and Di Giusto study, the test environment aimed to increase patient ease and relaxation by including comfortable padded seats, reading material for patients, large windows overlooking a garden, and piped music played at low volume. However, this study was conducted on an adult population, and excluded patients requiring a tooth extraction or those who had other stress-inducing problems. Our study, on the other hand, included participants regardless of their visit purpose.

In regards to the pediatric population, it has been suggested that waiting rooms designed for children can reduce their anxiety. Studies have found that positive dental images reduce anxiety compared with neutral images $[5,6]$. In addition, viewing positive images of dentistry and dentists was correlated with short-term reductions in anticipatory anxiety in children $[5,6]$. Panda et al. [20] evaluated 212 children between 6 and 11 years of age, and found that majority of children preferred music and the ability to play in a waiting room. They also preferred natural light and walls with pictures. Children favored gazing at an aquarium or watching television; as well as, sitting on beanbags and chairs. They were fond of plants and oral hygiene posters [15].

In our study, anxiety was found to be correlated with visit purpose. Children waiting for dental examination or those scheduled for dental treatment with conscious sedation were less anxious than children waiting for emergency treatment. Since groups differed by visit purpose it is difficult to conclude about the effect of waiting environment according to visit purpose. It can be expected that children waiting for treatment after receiving a dose of premedication will be less anxious prior treatment as a result of the medication. Children presenting for dental

Table 3 Mean VPT scores and visit purpose

\begin{tabular}{|c|c|c|c|}
\hline \multirow[t]{2}{*}{ Visit purpose } & \multicolumn{3}{|c|}{ Mean VPT (SD) } \\
\hline & $\begin{array}{l}\text { Total } \\
(N=113)\end{array}$ & $\begin{array}{l}\text { Test Group } \\
(N=56)\end{array}$ & $\begin{array}{l}\text { Control Group } \\
(N=57)\end{array}$ \\
\hline Examination & $1.14(1.56)$ & NA & $1.14(1.56)$ \\
\hline Emergency & $3.92(1.66)$ & 7 & $3.67(1.44)$ \\
\hline Treatment- no sedation & $1(2)$ & 0 & $2(2.83)$ \\
\hline Treatment with preoperative sedation- midazolam & $1.94(2.66)$ & $1.61(2.15)$ & $2.78(3.70)$ \\
\hline Treatment with preoperative sedation- atarax & $1.78(2.23)$ & $1.96(2.35)$ & $1.35(1.96)$ \\
\hline Treatment with preoperative sedation- valium & $1(1.73)$ & $1(1.73)$ & NA \\
\hline Treatment with inhaled sedation- $\mathrm{N}_{2} \mathrm{O}$ & $0.5(1)$ & 0 & $1(1.41)$ \\
\hline Overall mean (SD) & & $1.71(2.27)$ & $2(2.28)$ \\
\hline T-Test & & $\mathrm{t}(95)=.668, p>.05$ & \\
\hline
\end{tabular}


Table 4 Associations between covariates and VPT scores using unadjusted and adjusted linear regression

\begin{tabular}{|c|c|c|c|c|c|}
\hline & & \multicolumn{2}{|c|}{ Unadjusted } & \multicolumn{2}{|l|}{ Adjusted } \\
\hline & & Slope & $P$-value & Slope & $P$-value \\
\hline \multirow[t]{2}{*}{ Waiting room type } & Conventional & reference & NA & reference & NA \\
\hline & Multisensory & -0.29 & 0.505 & -0.46 & 0.272 \\
\hline Age & & -0.16 & 0.133 & -0.17 & 0.099 \\
\hline Waiting time (minutes) & & 0.23 & 0.019 & 0.24 & 0.013 \\
\hline \multirow[t]{2}{*}{ Gender } & Male & reference & NA & reference & NA \\
\hline & Female & -0.59 & 0.167 & -0.68 & 0.108 \\
\hline
\end{tabular}

check-up should be less anxious than those who are aware of the need for dental treatment due to pain or another emergency. Peretz and Kharouba [21] reported high dental anxiety among patients who expected operative procedures. Soares et al. [22] also found differences in dental anxiety in children associated with the visit purpose when analyzing three treatment types: preventive care, endodontic treatment, and dental extraction. Coffey and Di Giusto [4] reported that anxiety levels were higher in adult patients who presented for the first time than in those who came for a subsequent visit [4]. These findings emphasize the need for establishing a dental home, having periodic check-ups, and scheduling routine dental visits; thus, it is proposed that preventing the need for emergency dental treatment in an unfamiliar environment can reduce children's dental anxiety.

This study found that longer waiting time was associated with higher anxiety. This finding corroborates previously published literature showing that anxiety levels are significantly higher in dental patients who waited for longer periods of time $[4,23]$. Dentists must make the effort to shorten the waiting time as possible. In contrast to other studies [24, 25], the current study did not find any relation between age or gender and dental anxiety, perhaps because it tested anxiety while waiting for treatment and not dental anxiety in general.

Table 5 Mean VPT scores and waiting time

\begin{tabular}{llll}
\hline $\begin{array}{l}\text { Waiting time } \\
\text { (minutes) }\end{array}$ & \multicolumn{3}{l}{ Mean VPT (SD) } \\
\cline { 2 - 4 } & $\begin{array}{l}\text { Total } \\
(N=113)\end{array}$ & $\begin{array}{l}\text { Test Group } \\
(N=56)\end{array}$ & $\begin{array}{l}\text { Control Group } \\
(N=57)\end{array}$ \\
\hline$<10$ & $1.92(2.51)$ & $1.8(2.29)$ & $2.14(2.93)$ \\
$10-19$ & $1.03(1.36)$ & $0.67(1.07)$ & $1.23(1.48)$ \\
$20-29$ & $1.86(2.73)$ & $3(3.61)$ & $1(2)$ \\
$30-39$ & $3(1.77)$ & $1.5(2.12)$ & $3.5(1.52)$ \\
$40-49$ & $2.5(2.17)$ & $0.5(0.71)$ & $3.5(1.91)$ \\
$50-59$ & $1.5(2.38)$ & 0 & $2(2.65)$ \\
$>60$ & $2.93(2.95)$ & $2.73(2.80)$ & $3.67(4.04)$ \\
Overall mean (SD) & & $1.71(2.27)$ & $2(2.28)$ \\
T-Test & & $\mathrm{t}(95)=.668, p>.05$ \\
\hline
\end{tabular}

This study was limited by the low overall anxiety in the study group, based on the low VPT scores. This limitation may have contributed to the non-significant findings in anxiety scores between patients treated in different waiting room environments. It is possible that conducting the study in a population with higher levels of anxiety would have different results. Another limitation was the difference in visit purpose between groups that may have affected the results and the ability to compare between them. In addition, due to the nature of the intervention; two different waiting areas with different designs, the participants and the examiner could not be blinded to the intervention. Although there was a potential for bias, it did not influence the results of this study as we found no significant difference in the anxiety of children.

In view of the limitations of the current study, future research should include a more heterogenous sample of anxiety levels and more homogeneity in visit purpose, such as comparing patients who present for similar types of dental procedures.

\section{Conclusions}

A sensory adapted waiting room environment may be less important in reducing children's anxiety prior to dental treatment. There was no difference according to waiting room type; however visit purpose and waiting time had a significant effect on dental anxiety scores. Children's dental anxiety can be reduced by preventing emergency treatments, scheduling routine dental visits and decreasing waiting time.

\section{Abbreviations \\ VPT: Venham Picture Test}

\section{Acknowledgements \\ Not applicable.}

\section{Authors' contributions}

AFN and DR conceived the ideas and designed the work; MZ, AS and EH collected the data; AFN, MZ and KH analysed the data; and AFN, DR, MM and $\mathrm{KH}$ led the writing. All authors have read and approved the manuscript.

Funding

No funding 


\section{Availability of data and materials}

Raw data is available in supplemental material.

\section{Ethics approval and consent to participate}

Study protocol was approved by the Institutional Human Subjects Ethics Committee of Hadassah Medical Organization (HMO-0678-16). Written informed consent was obtained from all parents/guardians of the participants included in the study.

\section{Consent for publication}

Written consent for publication obtained from all parents/guardians of the participants included in the study.

\section{Competing interests}

The authors declare that they have no competing interests.

Received: 2 July 2019 Accepted: 19 December 2019

Published online: 30 December 2019

\section{References}

1. Klingberg G, Broberg AG. Dental fear/anxiety and dental behaviour management problems in children and adolescents: a review of prevalence and concomitant psychological factors. Int J Paediatr Dent. 2007;17:391-406

2. Eli I, Uziel N, Baht R, Kleinhauz M. Antecedents of dental anxiety: learned responses versus personality traits. Community Dent Oral Epidemiol. 1997; 25:233-7.

3. Peretz B, Efrat J. Dental anxiety among young adolescent patients in Israel. Int J Paediatr Dent. 2000;10:126-32.

4. Coffey PA, Di Giusto J. The effects of waiting time and waiting room environment on dental patients' anxiety. Aust Dent J. 1983:28:139-42.

5. Gangwal RR, Rameshchandra Badjatia S, Harish DB. Effect of exposure to positive images of dentistry on dental anxiety among 7 to 12 years old children. Int J Clin Pediatr Dent. 2014;7:176-9.

6. Fox C, Newton JT. A controlled trial of the impact of exposure to positive images of dentistry on anticipatory dental fear in children. Community Dent Oral Epidemoil. 2006;34:455-9.

7. Hasheminia D, Kalantra Motamedi MR, Karimi Ahmadabadi F, Hashemzehi H, Haghighat A. Can ambient orange fragrance reduce patient anxiety during surgical removal of impacted mandibular third molars? J Oral Maxillofac Surg. 2014;72:1671-6.

8. Kritsidima M, Newton T, Asimakopoulou K. The effects of lavender scent on dental patient anxiety levels: a cluster randomized-controlled trial. Community Dent Oral Epidemiol. 2010;38:83-7.

9. Klassen JA, Liang Y, Tjosvold L, Klassen TP, Hartling L. Music for pain and anxiety in children undergoing medical procedures: a systematic review of randomized controlled trials. Ambul Pediatr. 2008:8:117-28.

10. Bradt J, Dileo C, Shim M. Music interventions for preoperative anxiety. Cochrane Database Syst Rev. 2013;6(6):CD006908. https://doi.org/10.1002/ 14651858.CD006908.pub2.

11. Miyata K, Odanaka H, Nitta Y, Shimoji S, Kanehira T, Kawanami M, Fujisawa T. Music before dental surgery suppresses sympathetic activity derived from preoperative anxiety: a randomized controlled trial. JDR Clin Trans Res. 2016; 1:153-62. https://doi.org/10.1177/2380084416650613.

12. Merrick J, Cahana C, Lotan M, Kandel I, Carmeli E. Snoezelen or controlled multisensory stimulation. Treatment aspects from Israel. ScientificWorld J. 2004:4:307-14

13. Shapiro M, Sgan-Cohen HD, Parush S, Melmed RN. Influence of adapted environment on the anxiety of medically treated children with developmental disability. J Pediatr. 2009:154:546-50.

14. Shapiro M, Melmed RN, Sgan-Cohen HD, Eli I, Parush S. Behavioural and physiological effect of dental environment sensory adaptation on children's dental anxiety. Eur J Oral Sci. 2007;115:479-83.

15. Cermak SA, Stein Duker LI, Williams ME, Dawson ME, Lane CJ, Polido JC Sensory adapted dental environments to enhance oral care for children with autism spectrum disorders: a randomized controlled pilot study. J Autism Dev Disord. 2015:45:2876-88.

16. Buchanan $\mathrm{H}$, Niven N. Validation of a facial image scale to assess child dental anxiety. Int J Paediatr Dent. 2002:12:47-52.

17. Goettems ML, Dos Santos CF, da Costa VPP. The challenge of child management during dental care: use of nonpharmacological approaches. Acad Pediatr. 2019;19:495-6.
18. Clinical Affairs Committee-Behavior Management Subcommittee, American Academy of Pediatric Dentistry. Guideline on behavior guidance for the pediatric dental patient. Pediatr Dent. 2015;3:57-70.

19. Jayakaran TG, Rekha CV, Annamalai S, Baghkomeh PN, Sharmin DD. Preferences and choices of a child concerning the environment in a pediatric dental operatory. Dent Res J (Isfahan). 2017;14:183-7.

20. Panda A, Garg I, Shah M. Children's preference concerning ambiance of dental waiting rooms. Eur Arch Paediatr Dent. 2015;16:27-33.

21. Peretz B, Kharouba J. Dental anxiety among Israeli children and adolescents in a dental clinic waiting room. Pediatr Dent. 2013;35:252-6.

22. Soares JP, Cardoso M, Bolan M. Demystifying behaviour and dental anxiety in schoolchildren during endodontic treatment for primary teeth - controlled clinical trial. Int J Paediatr Dent. 2019. https://doi.org/10.1111/ipd.12468.

23. Kheir OO, Ziada HM, Abubakr NH, Abdel-Rahman ME, Fadl SM, Ibrahim YE. Patient-dentist relationship and dental anxiety among young Sudanese adult patients. Int Dent J. 2019;69:35-43.

24. Oba Y, Dülgergil C, Sönmez I. Prevalence of dental anxiety in 7- to 11-year-old children and its relationship to dental caries. Med Princ Pract. 2009;18:453-7.

25. Carvalho RW, Falcão PG, Campos GJ, Andrade ES, Vasconcelos BC, Pereira MA. Prevalence and predictive factors of dental anxiety in Brazilian adolescents. J Dent Child (Chic). 2013;80:41-6.

\section{Publisher's Note}

Springer Nature remains neutral with regard to jurisdictional claims in published maps and institutional affiliations.
Ready to submit your research? Choose BMC and benefit from:

- fast, convenient online submission

- thorough peer review by experienced researchers in your field

- rapid publication on acceptance

- support for research data, including large and complex data types

- gold Open Access which fosters wider collaboration and increased citations

- maximum visibility for your research: over $100 \mathrm{M}$ website views per year

At $\mathrm{BMC}$, research is always in progress.

Learn more biomedcentral.com/submissions 